\title{
EXPERIMENTAL STUDIES ON THE GENERATION OF WAVES IN SHALLOW WATER
}

\author{
C. T. Kuo \\ Associate Professor \\ Frederick L. W. Tang, Dr. Eng. \\ Profeseor and Chairman \\ Hydraulic Engineering Department \\ Cheng Kung University \\ Tainan, City, Taiwan \\ Republic of China
}

\section{SYNOPSIS}

The seas in front of China coast such as Yellow Sea, East China sea and Taiwan straito are all located on continental shelf. In coneequence, waves approaching these coasts are generated in shallow water area in comparsion with wave length. The author has developed tangible calculation procedures for evaluating the wave features in such areas in stationary or moving fetches (1). However, the basical formulas of calculation are derived from experimental data of Bretechneider and Thijese. In order to investigate the generating process of shallow water wind waves and obtain more detailed informations for correcting calculation criteria, a series of experiments have been performed at a wind tunnel of 75 meters in length. Various investigations on the relationships between waves and wind as well as water depth ard to be submitted in this paper.

In addition, the situation of wind wave coexistance with regular wave is studied from experiments, because it resembles the aperposition of refracted and local wind waves on the western coast of Taiwan.

\section{SIGNIFICANT WAVE FEATURES}

From the experiments, the wave heights and periods increase with wind velocities and fetch lengths, however, they reach fully arion state more rapidly than deep water waves, only a fow minutes in the experiments. After fully arisen, a portion of high waves begin to break and reduce their heights slightly, however, the waves recover their heights after advancing a shovt distance and then they break partially, auch phenomena repeat again and again especially in the cases of the wind being strong. The ware periods remain increasing within the fetch length in these experiments, however, it can be expected that the wave periods and heights may become constant if the fetch length is long enough. 
The experimantal curves of $6 H_{1} / U^{2}$ versus $G F / U^{2}$ with perameter $\mathrm{Gd} / \mathrm{U}^{2}$ as shown in $\mathrm{Fig}_{\mathrm{g}} \mathrm{I}^{3}$ have the same tendency with the curves of Bretschneider (2), however, our data are larger than those of Johnson, Huft and Hawada, and oven larger than the values predicted from the fotch graph of SMB in the region of $\mathrm{gF}^{\mathrm{F}} / \mathrm{U}^{2}$ in Fig. 2 are located below breaking lint and Bretschneider's seady state of friction coefficients equal to 0.01 . In Fig. 3 the experimental result of the relationship between $\mathrm{gT}_{\frac{1}{3}} / \mathrm{V}$ versus $\mathrm{gF}^{\mathrm{F}} / \mathrm{U}^{2 /}$ is guite agreed with deep water waves.

Statistical characteristics of wave helghts and periods have also been calculated. As hown In Fig. 4 and 5 the probability distribution corresponds sufficiently to Gaussian's rather than Rayleigh's. The ratias between various $1 / n$th wave helghts are as follows.

$$
\begin{aligned}
& H_{y /} / H_{\text {ave }}=1.38 \\
& H_{y / d} / H_{1 / 3}=1.16 \\
& H_{\max } / H_{1 / 3}=1.39
\end{aligned} \quad\left\{\begin{array}{l}
1.60 \\
1.27 \\
1.64
\end{array}\right)
$$

Any of the numbers 18 smaller than the theoretical value of Longuet-Higgins (in parenthesis). The ratios of $1 / n$th wave helght to root-mean-square wave helght Hrms are as follows.

$$
\begin{aligned}
& \mathrm{H}_{\text {avd }} / \mathrm{H}_{\mathrm{rms}}=0.94 \\
& \mathrm{H}_{1 / 3} / \mathrm{H}_{\mathrm{rms}}=1.30 \\
& \mathrm{H}_{\mathrm{K}_{0}} / \mathrm{H}_{\mathrm{rms}}=1.55
\end{aligned}
$$

They ceen to be little concern with spectral widh paraneter.

On the whole, there 18 no substantial difference botween the statistioal properties of wind waves in shallow and deep water.

\section{SPECTRAL ANALYSIS}

The power epectra are calculated from experimental records by Blackman-Tukey' method. Sampling time interval it is $1 / 10-$ $1 / 15$ sec., total number of data $18 \mathrm{~N}=800$, maximua time lag a equals 40 , and folding frequency $\mathrm{fm}=5 \mathrm{cps}$ (or $0.375 \mathrm{cps}$ ). The degree of freedom calculated by Tukeys formula 1 s 40 , is consequence, confidence limit in $10 \%$ is $0.73-1.30$.

At early stage, the spectra grow continuousiy as the fetch length boconing longor tili saturation tate 1 seached. While the fetch lengths extend, the lower frequency parts of the epectral curves increase their densty, as Fig. $6,7,8$. 
The relationship between wave spectra and wind raloeity has the eame teldency of deep water waves. Namely in sane fetch length and water depth, the spectra grow with wind velocity being Increasing. As Fig. 9 o 11 , if the depth 1 . sma11, the epeotral denaity 1 omaller than that of deep water waves, as chown in Fig. 12, 13, 14, for oame witd velocitJ. The greater the wind velocity is the earlier the low frequency portion of epectrum developed, and the wider the frequency band becomes. In any case, the high frequency side of equilibrium range decade remarkably and can be represented by $f^{-n}$.

The oonnection between $T / 3$ and optimum period Top 18 to be $T y_{3}=1.23$ Top $1 n$ our experiments, and $T / / 3=1.23$ Tave $=1.23$ irme, accordingly Trms = Tave = Top.

Phillpo pointed out thy shape of spectral curves in high frequency aide should be:

$$
\Phi(f)=\beta E^{2} f^{-5}
$$

However, Hamada proved that $\bar{\Phi}(\mathrm{f})^{5}=\beta \mathrm{g}^{2} \mathrm{r}^{-n}$, and $\mathrm{n}$ w111 be larger than 5 in deep water wave spectra. Our experimento also reveal $n=7-10$ in shallow water waves.

The relationahip between $H$ and $E=2 \int \Phi(f)$ dr 1 e the same as deep water waves, namely $H / / 3=2.83 \sqrt{\mathrm{E}}$. As ohom in Fig. 15 .

\section{STUDIES ON THE COPERPOSITION OF REGULAR AND WIND WAVES}

According to the special topography of western coast of Taiwan, the beach is very flat and the waves approach from Taiwan Straite are breaking on offehore vare. The distanoe between bare and the wain coast or sea dike 18 otill a 1 ong as $5 \mathrm{~km}$. Loonl wind waves are overlapping on the waves after broken. To investigate such a phenomenon in order to offer design criteria for sea dikes, we generated regular waves by flap type wave generator and blow wind simultaneousiy in the same wind wave channel. The regular wave spectra are shown in Fig. 16 and the opectra of wind wave while regular wave are not to be existing are ahown in Fig. 17 . Fig. 18 shows the result spectra of overlapping. Apparently there are two kinde of wave existing independently. However, if the regular wave steopmeas is large such a phenomenon disappears as Fig. 19. The compriton of the energy of resultant wave energy and energy calculated by linear sumbation 1 s shown in Fig. 20. In case of broken waves superposed by wind waves as the case of western coast of Taiwan. Wave helght in front of sea dike can be approximately calculated by $\mathrm{H}^{2}=\mathrm{Hw}^{2}+\mathrm{H}_{\mathrm{R}}^{2}$. 


\section{CONCLUSTON}

From experimental data described above following conclusions can be made.

1. The generation procedure of shallow water waves is closed resembling to deep water waves, however, the duration for fully arisen is much shorter.

2. In the range of our experiments wave period seems not to be ignificantly influented by water depth. The wave height increases with fetch length increasing, however, they are smaller than deep water waves due to the influence of water depth.

3. If wave spectra of shallow wave area are available, the significant wave height can also be calculated by $\mathrm{H} \mathrm{Y}_{3}=2.83 \sqrt{\mathrm{E},}(\mathrm{E}=2 / \mathscr{f}(\mathrm{f}) \mathrm{df})$.

4. In the problem concerning superposition of two series of waves, if the oteepness is small, the resultant wave heights can be calculated by linear summation of their energies.

\section{REFERENCE}

1. Froderick L. W. Tang: Researches on Calculation of Waves on Long Shoaling Beaches. Jour. of Civil and Hydraulic Engineering, Taiwan Provincial Cheng Kung University. Feb. 1970.

2. Breschneider: Generation of Wind Waves Over a Shallow Bot tom. B. E. B. Tech. Memo No. 51 Oct. 1954. 


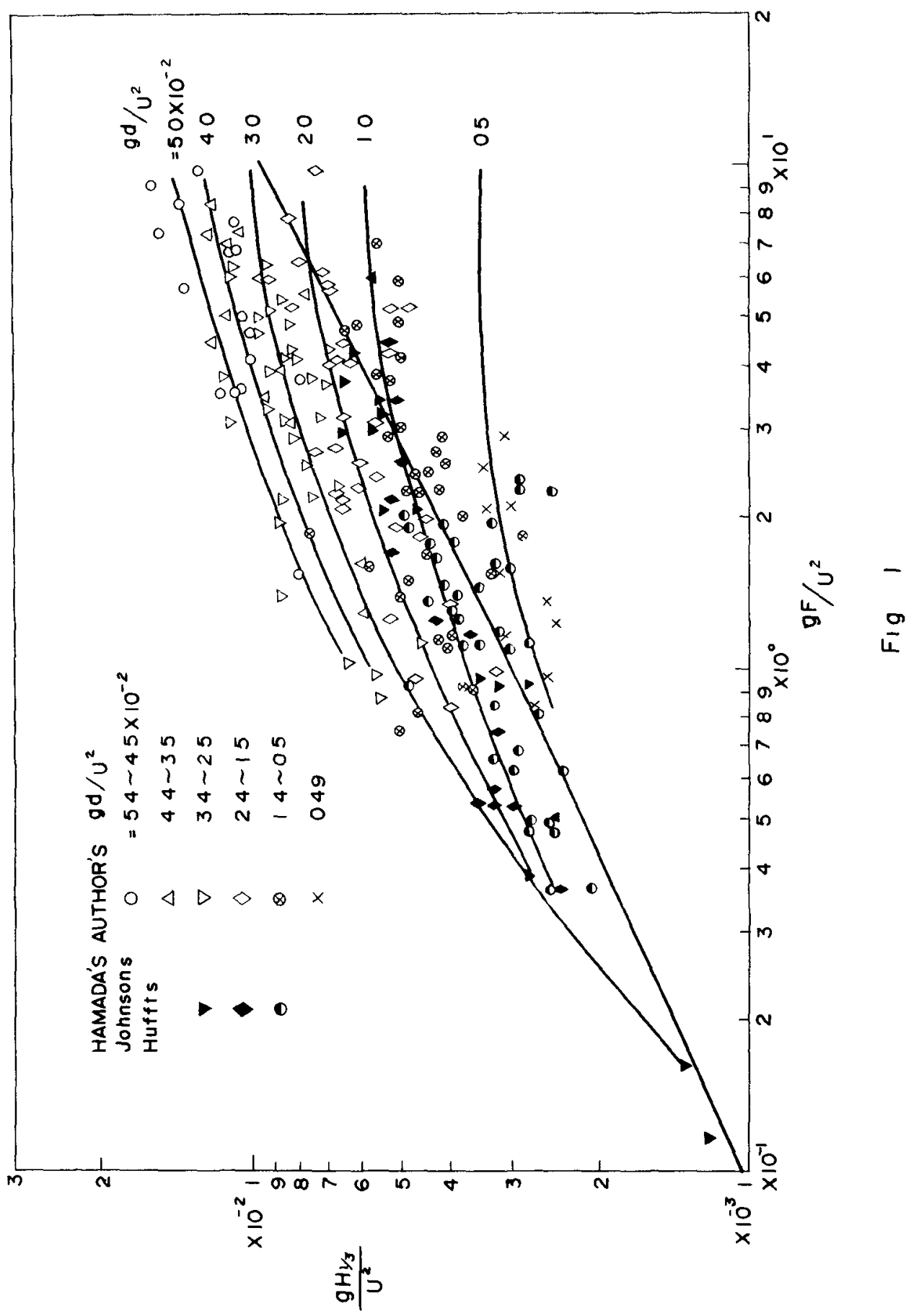




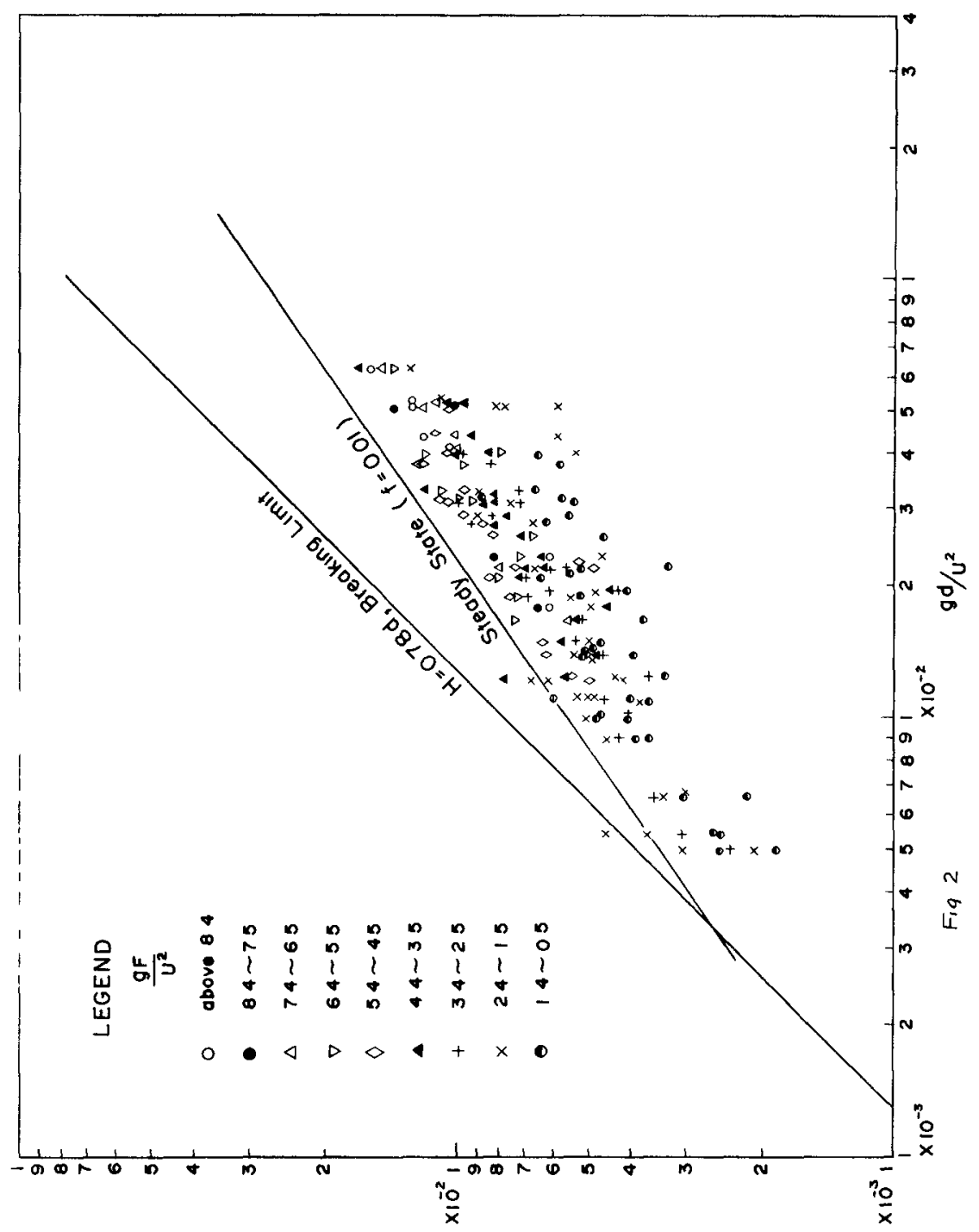

部 


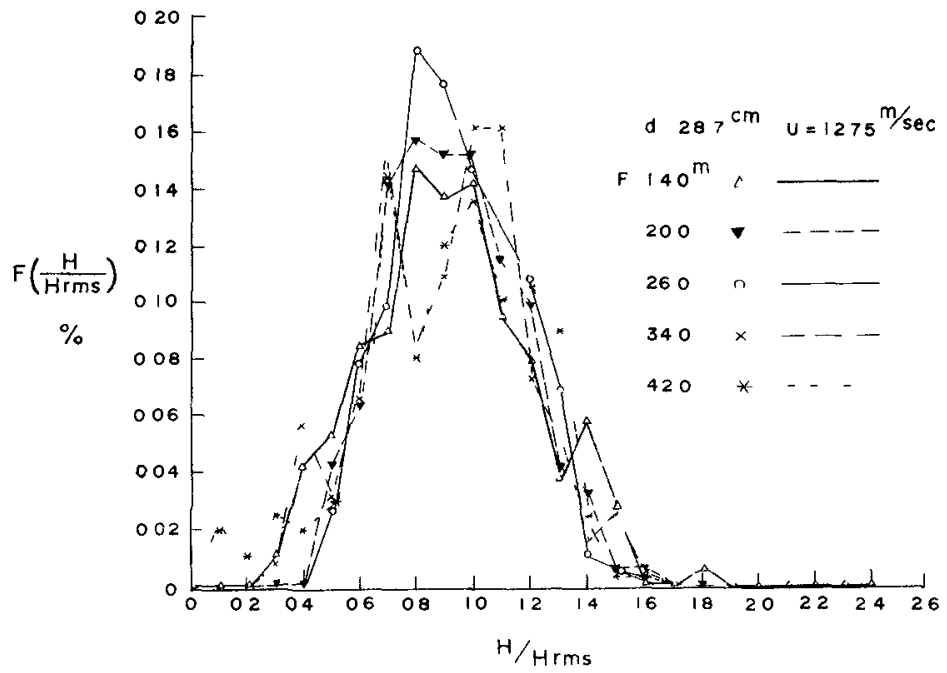

FIg 4

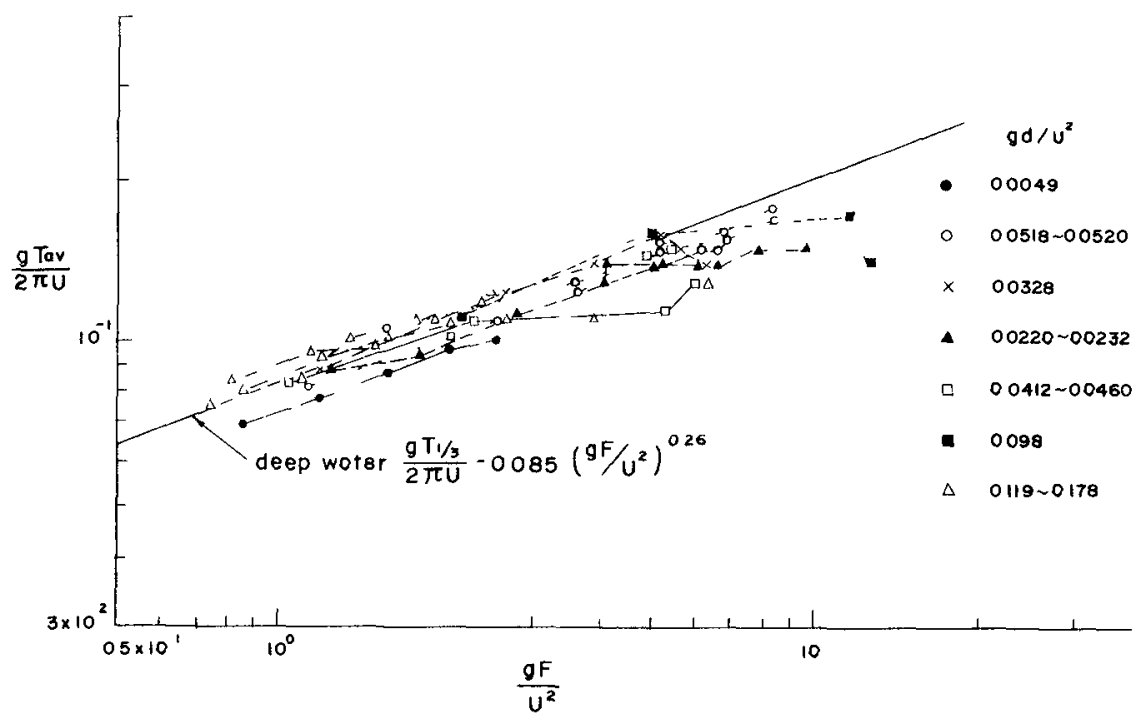






Fig 5 


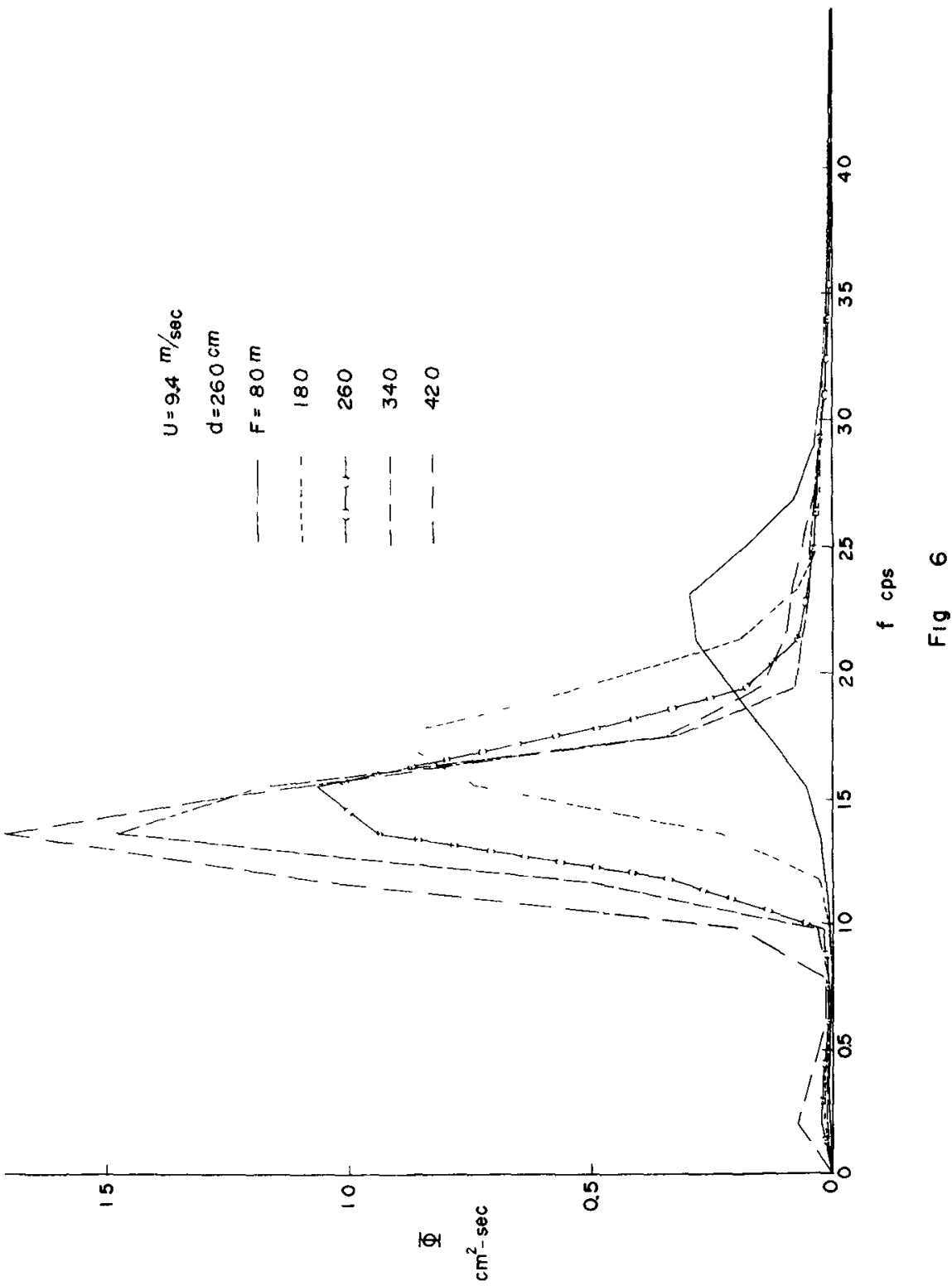




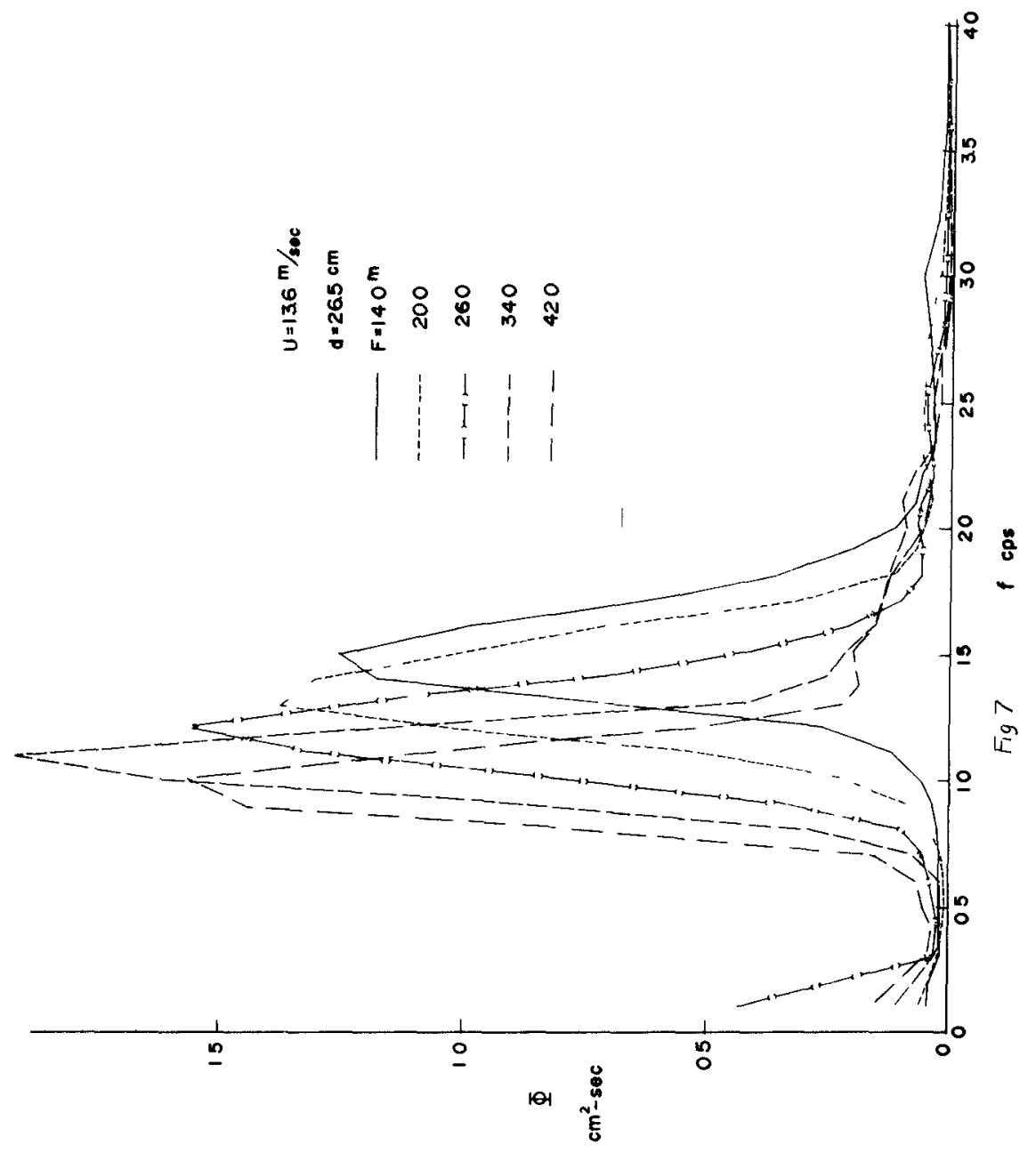




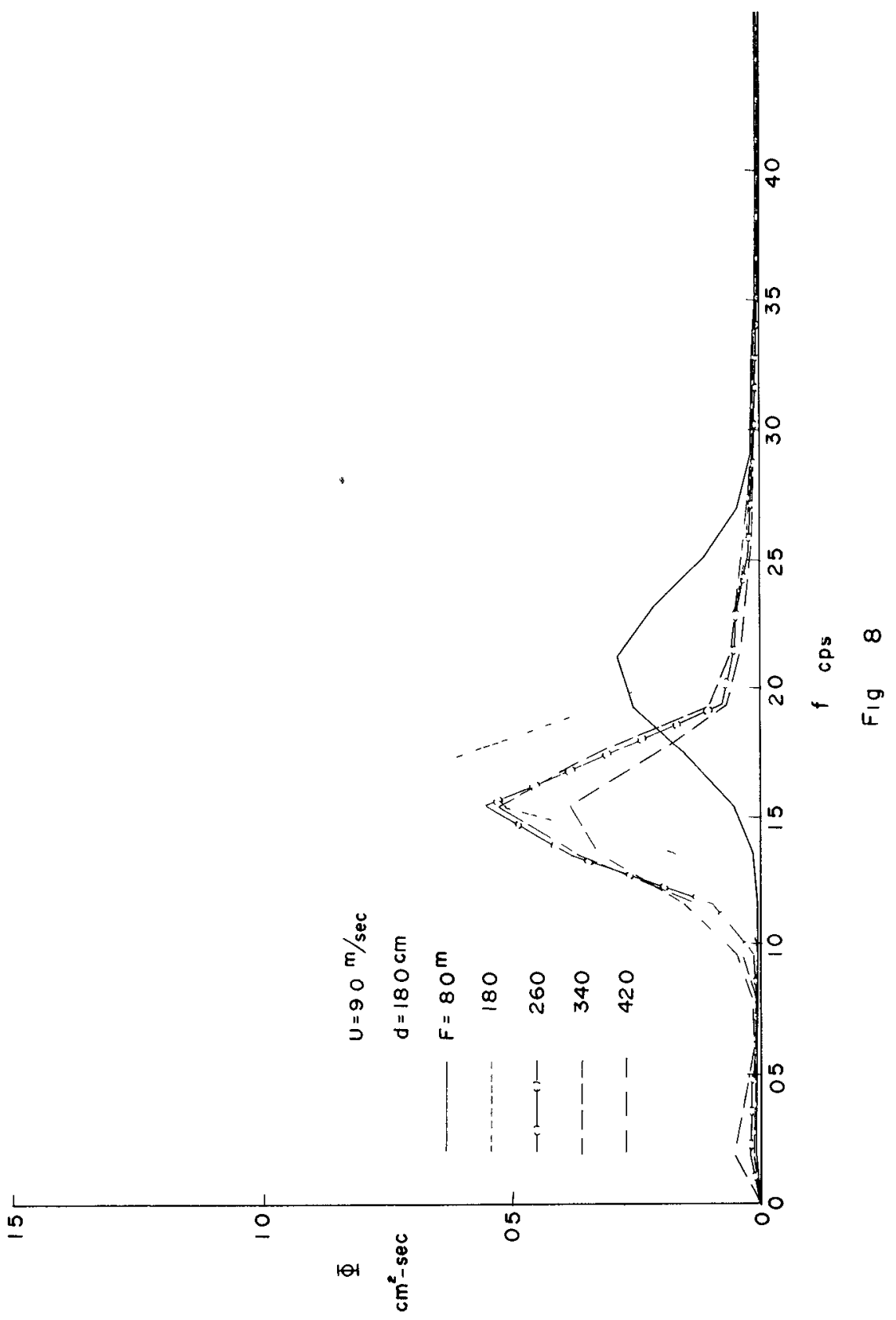




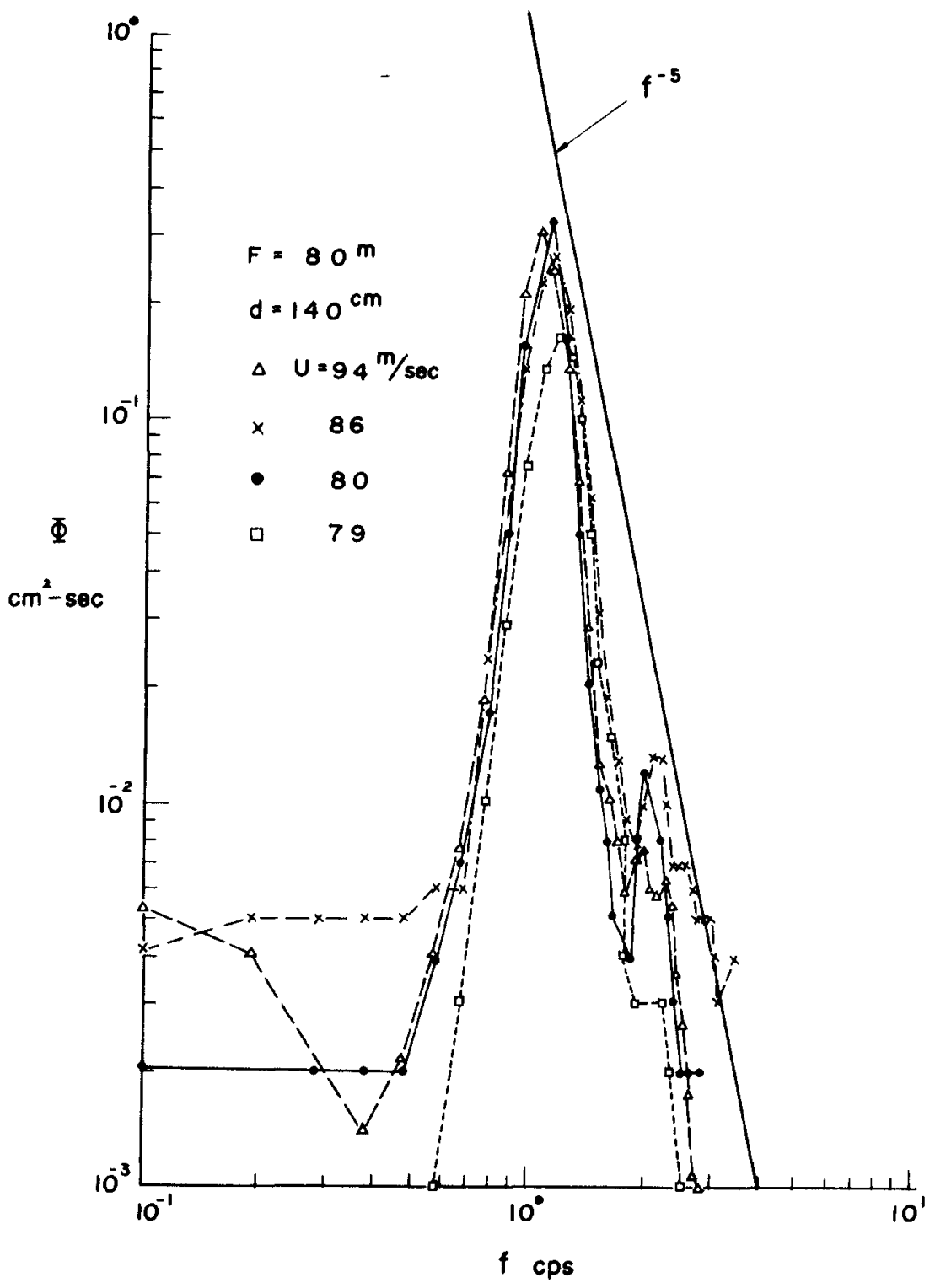

Fig 9 


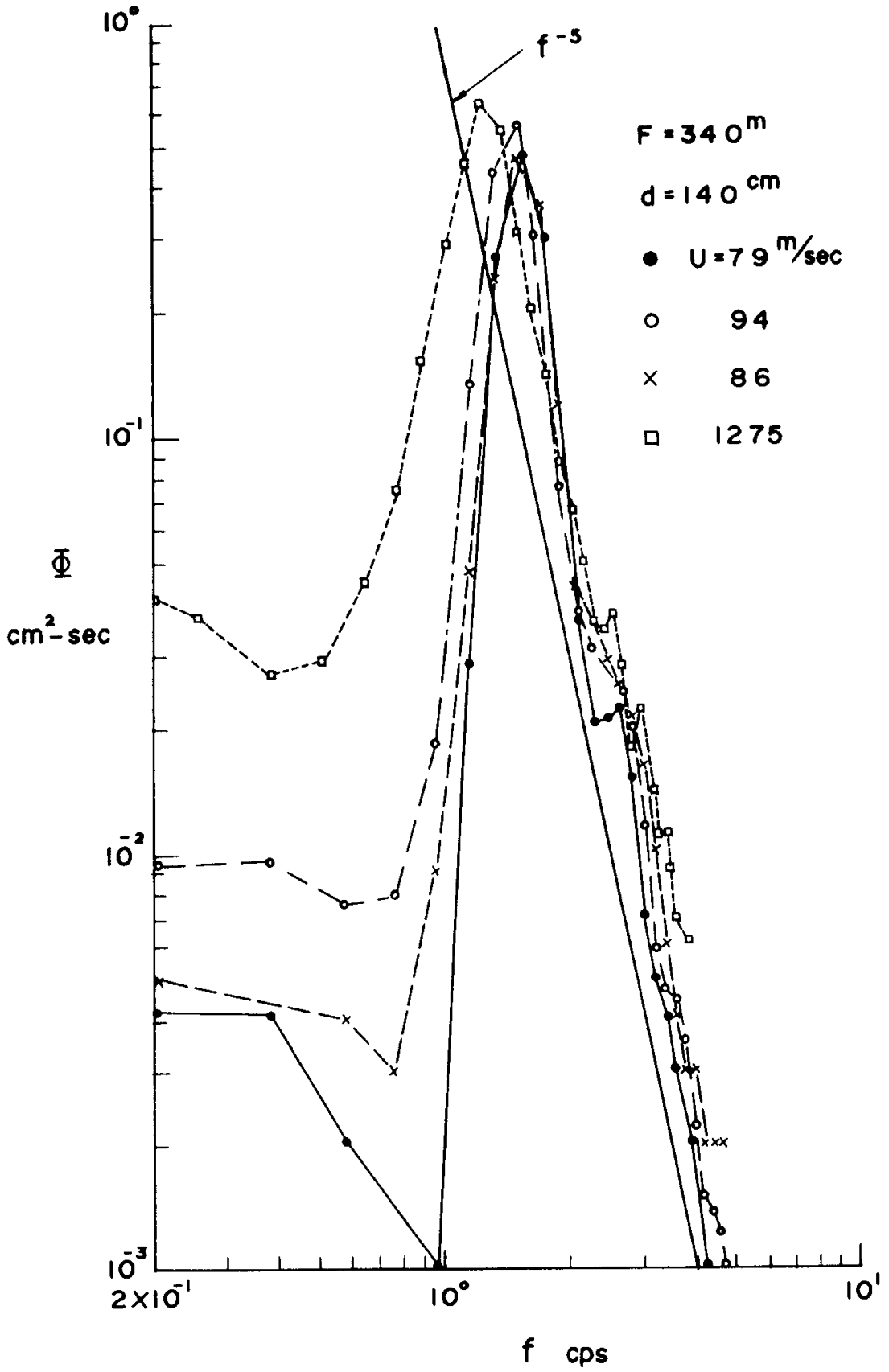

Fig 10 
192

COASTAL ENGINEERING
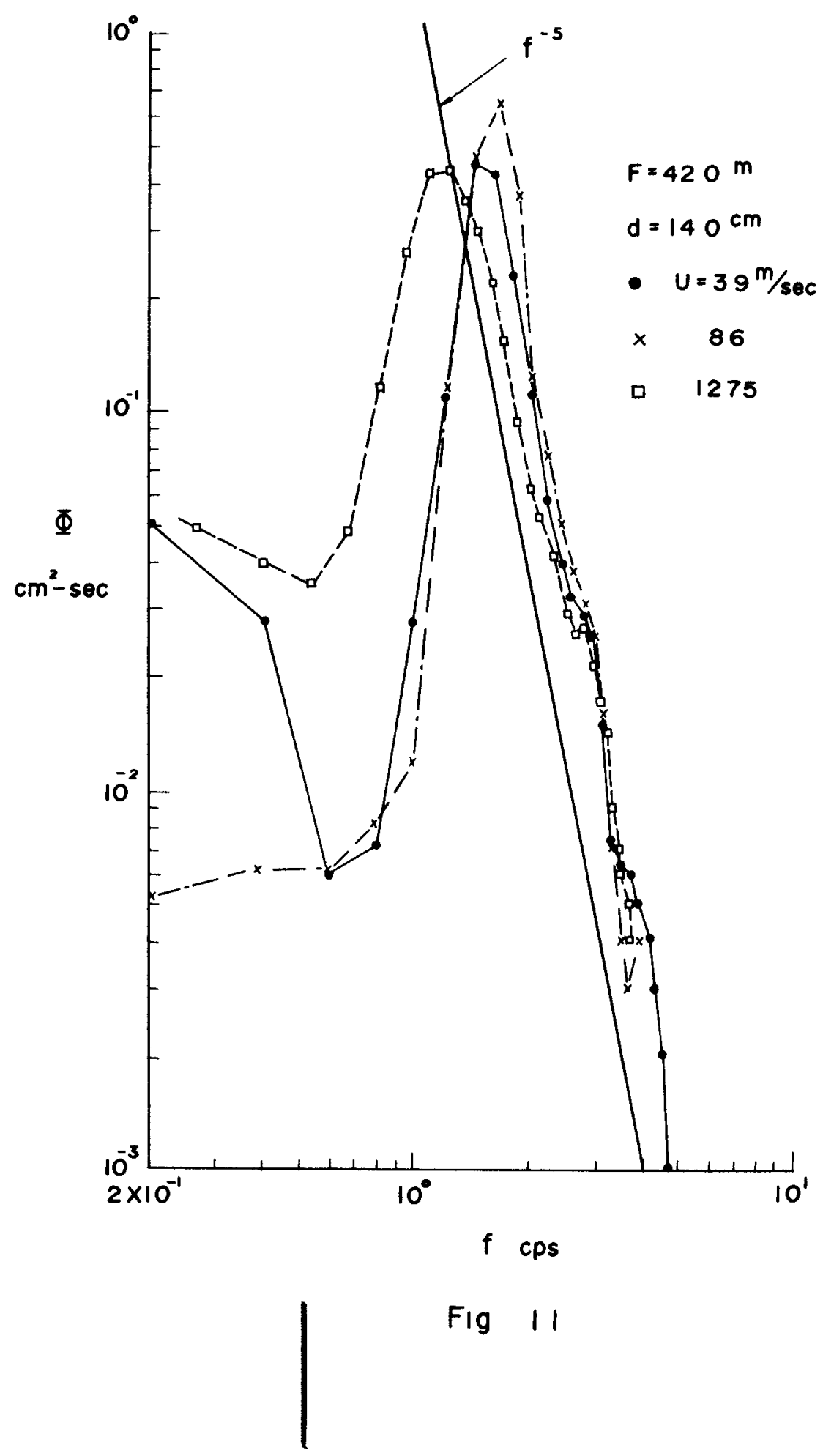

Fig 11 


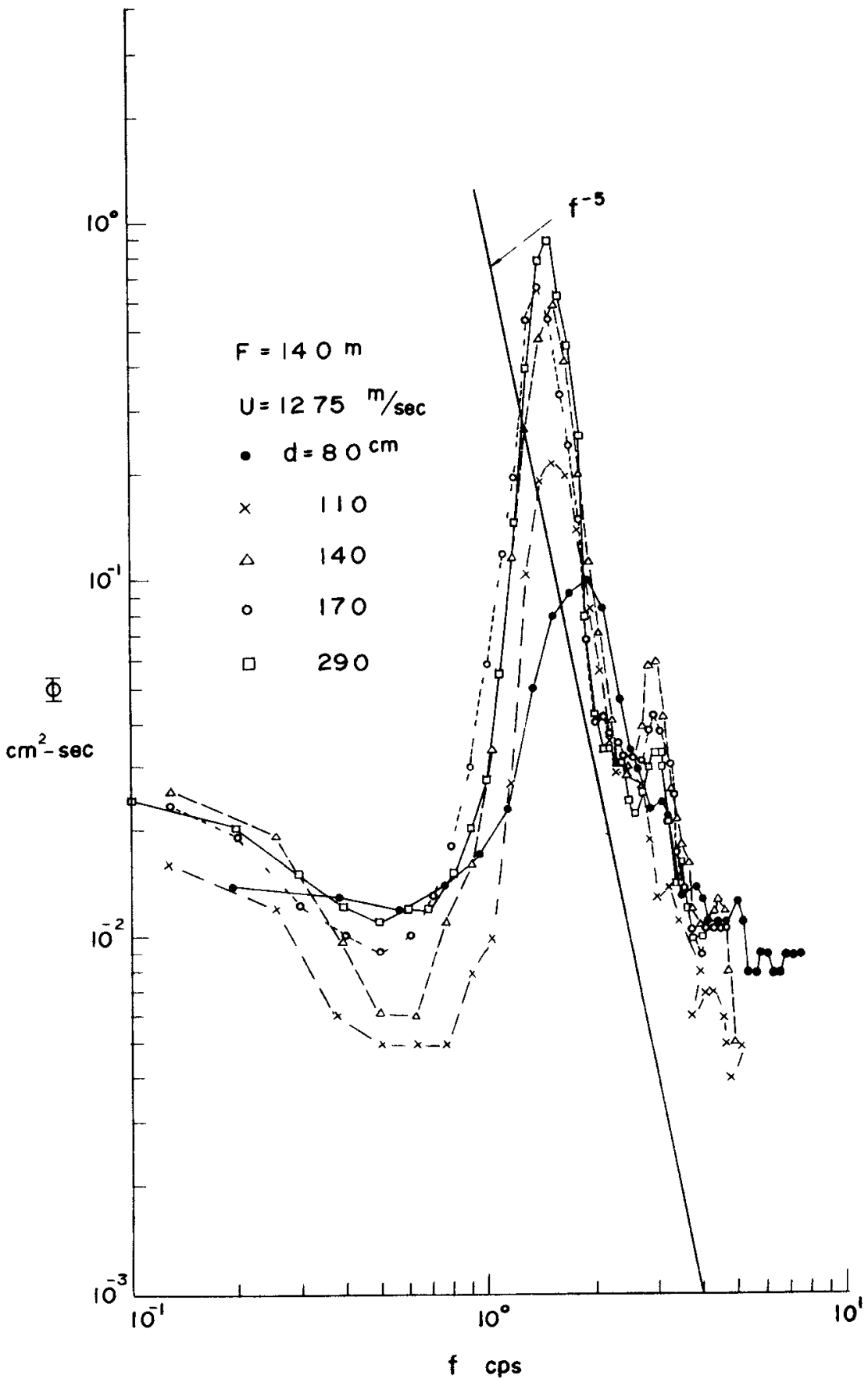

Fig 12 


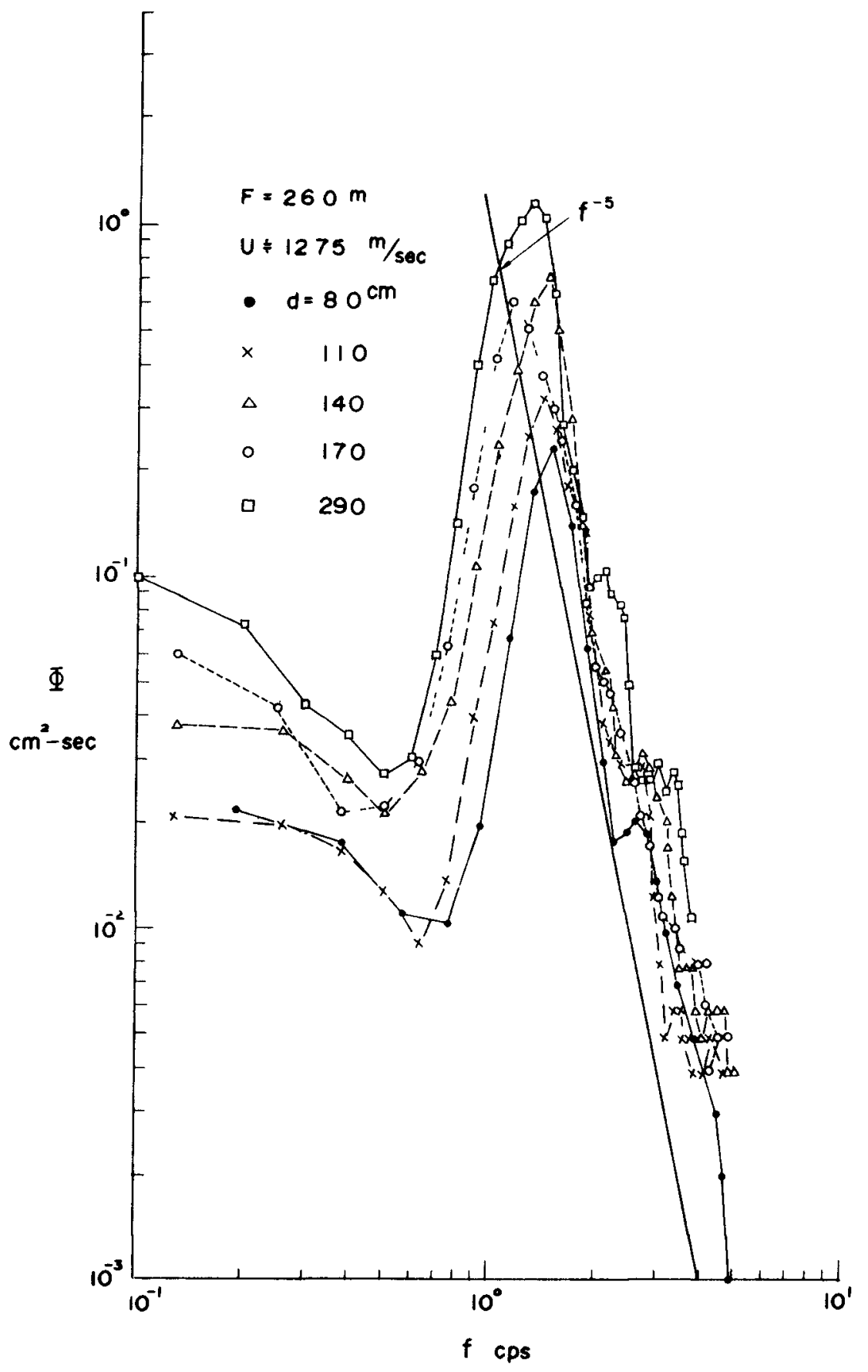

Fig 13 


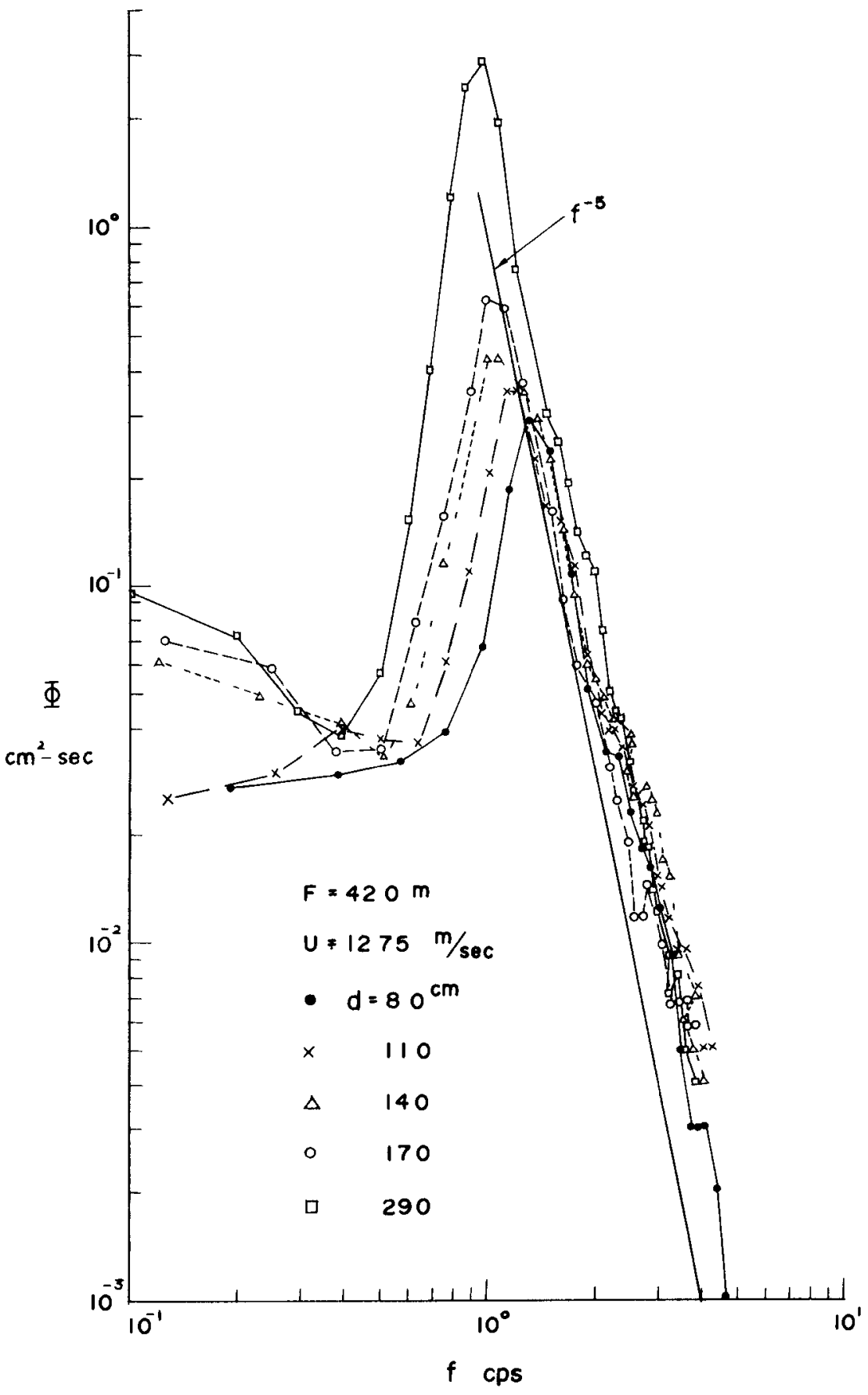

Fig 14 


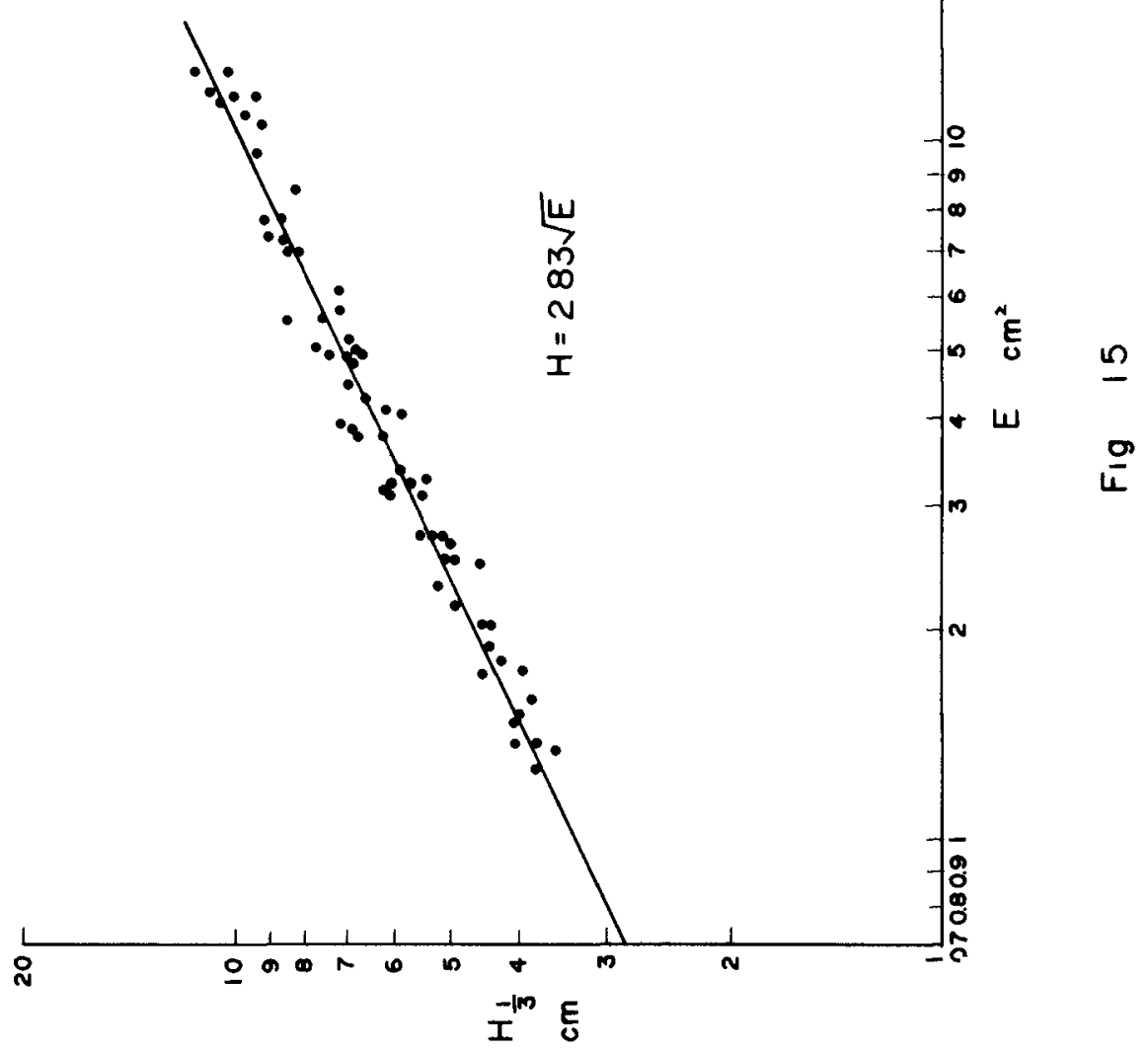


SHALLOW WATER

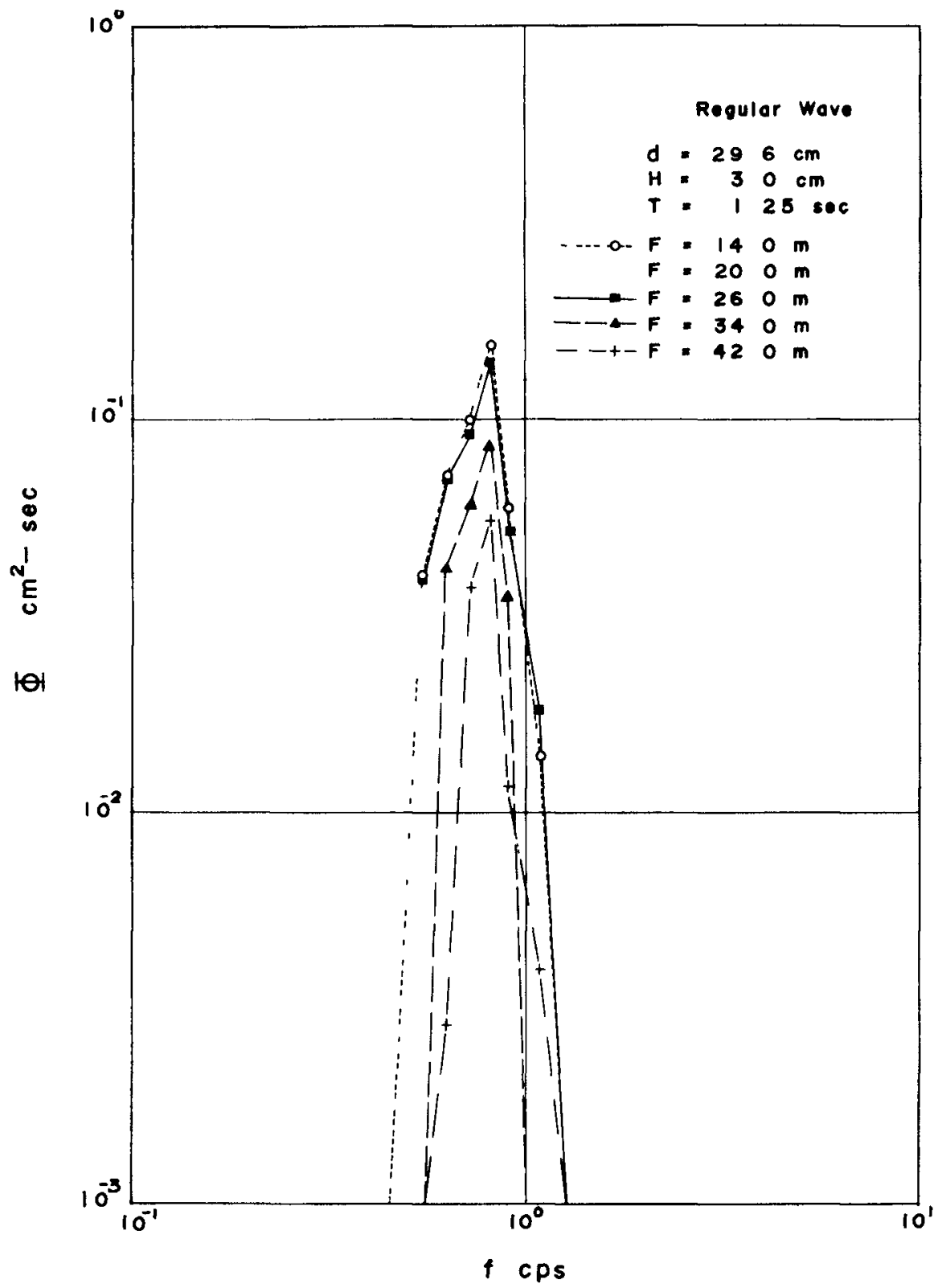

Fig 16 


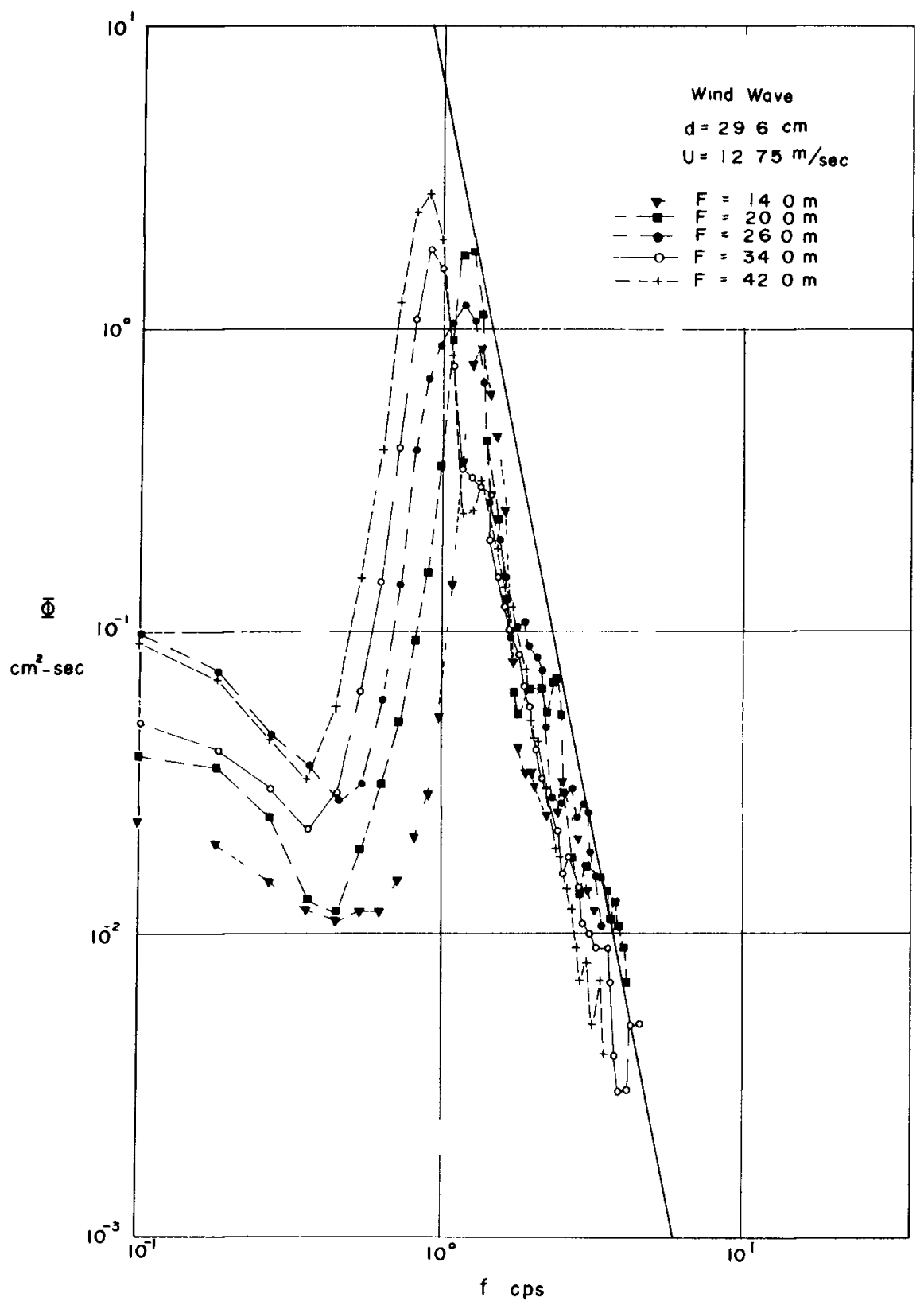




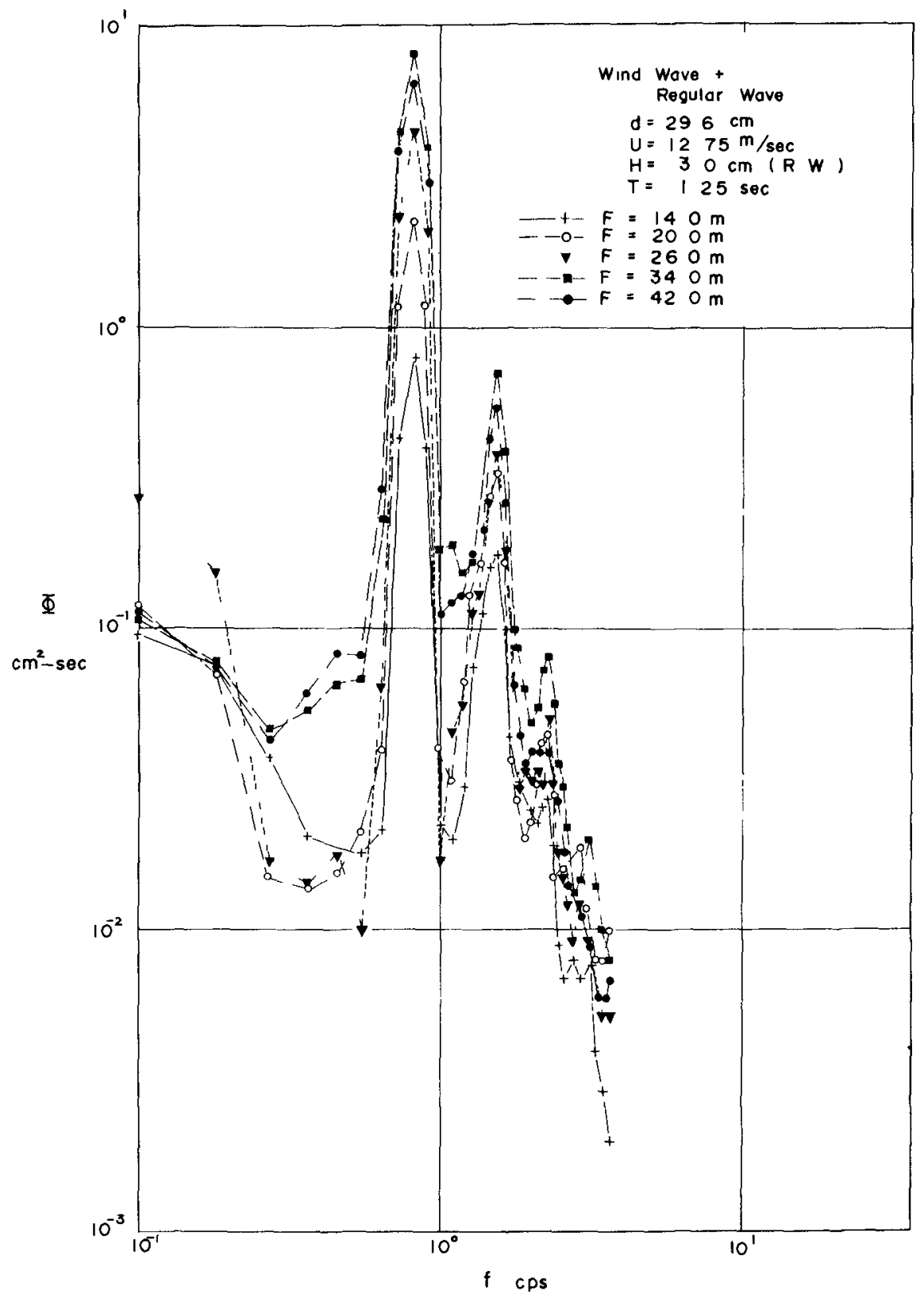

Fig 18 


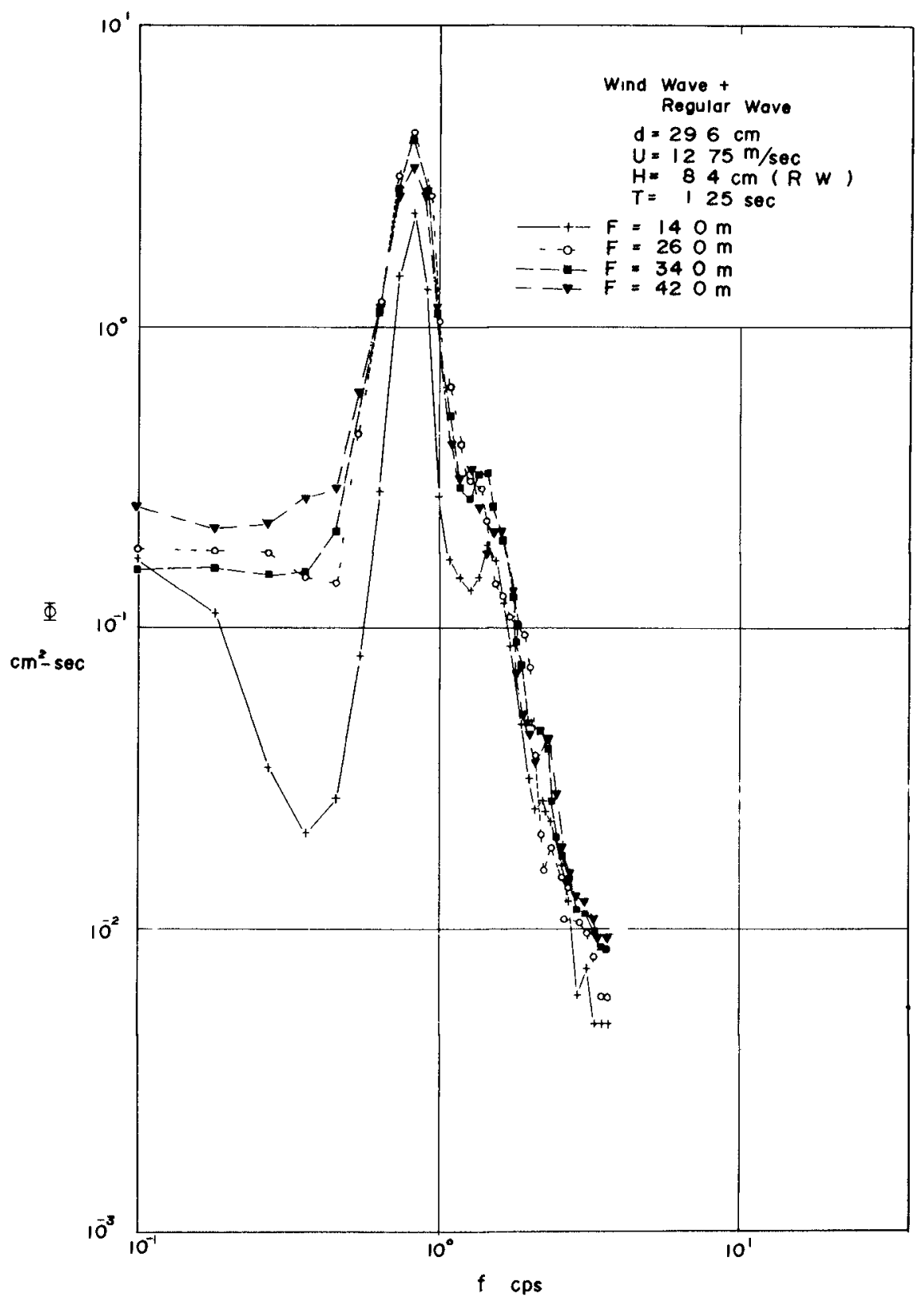

Fig 19 


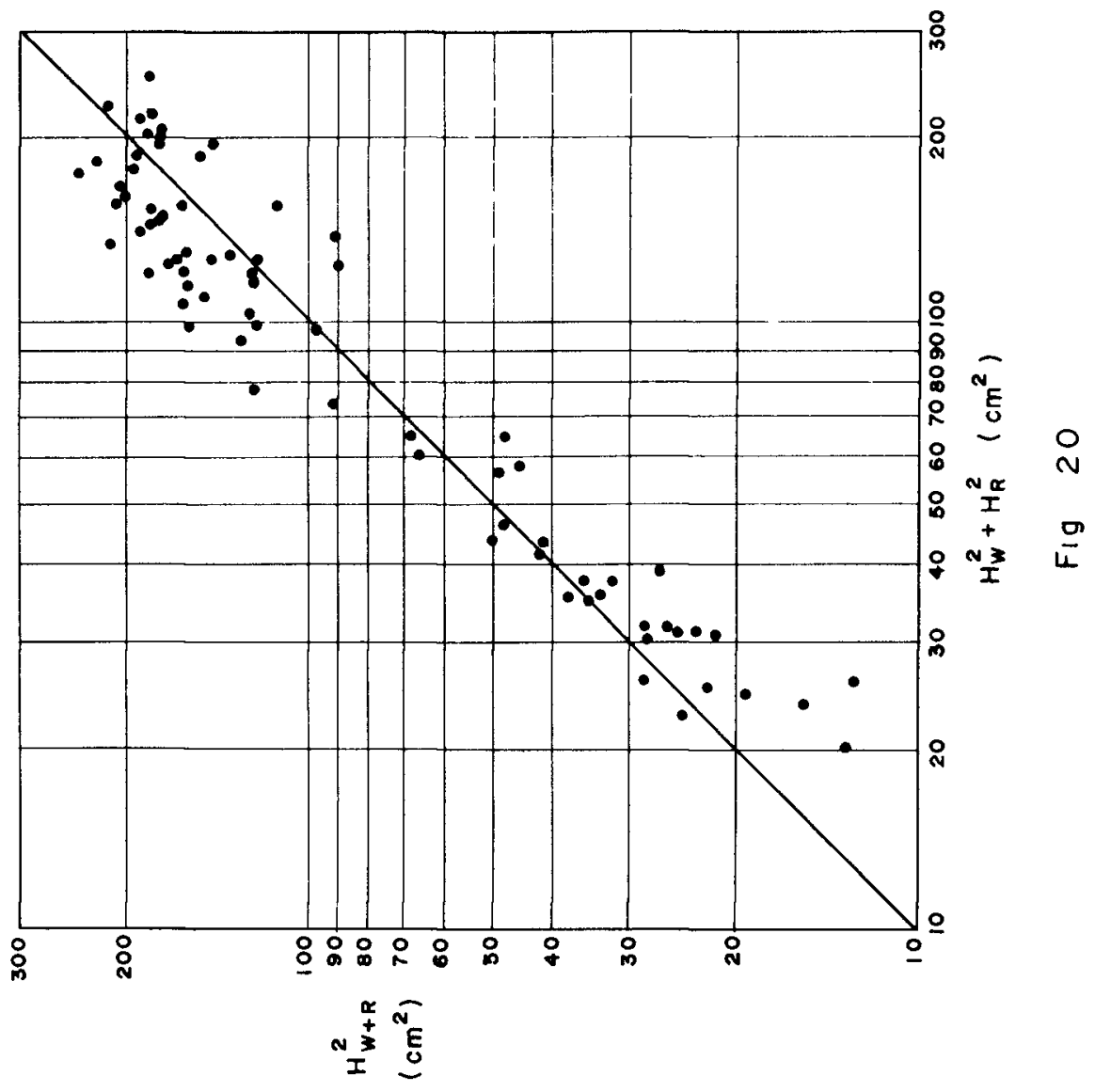


